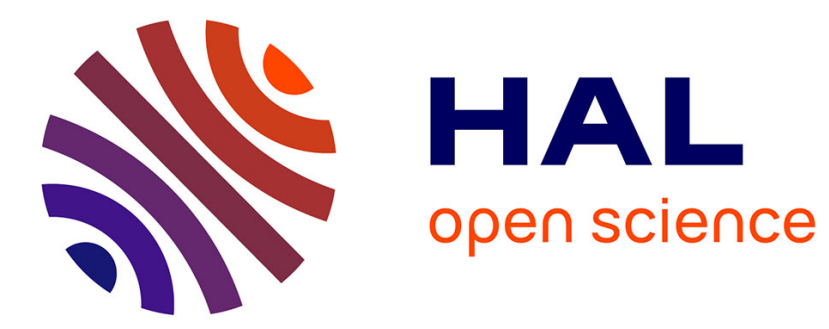

\title{
Photothermal spectroscopy of CdSxSe1-x doped glasses
}

\author{
T. Toyoda, H. Shin-Yasu
}

\section{To cite this version:}

T. Toyoda, H. Shin-Yasu. Photothermal spectroscopy of CdSxSe1-x doped glasses. Journal de Physique IV Proceedings, 1994, 04 (C7), pp.C7-365-C7-368. 10.1051/jp4:1994785 . jpa-00253315

\section{HAL Id: jpa-00253315 https://hal.science/jpa-00253315}

Submitted on 1 Jan 1994

HAL is a multi-disciplinary open access archive for the deposit and dissemination of scientific research documents, whether they are published or not. The documents may come from teaching and research institutions in France or abroad, or from public or private research centers.
L'archive ouverte pluridisciplinaire HAL, est destinée au dépôt et à la diffusion de documents scientifiques de niveau recherche, publiés ou non, émanant des établissements d'enseignement et de recherche français ou étrangers, des laboratoires publics ou privés. 


\title{
Photothermal spectroscopy of $\mathrm{CdS}_{x} \mathrm{Se}_{1-x}$ doped glasses
}

T. Toyoda and H. Shin-Yasu(1)

Department of Applied Physics and Chemistry, The University of Electro-Communications, 1-5-1 Chofugaoka, Chofu, Tokyo 182, Japan

\begin{abstract}
Photothermal spectroscopy using thermistor is applied to study the heat generation of glasses containing a small amount of thermally developed CdS $S_{S_{1-x}}$ microcrystalline phases together with the optical absorption character. They show that the increase of signal intensity of heat generation is different from that of optical absorption. The width of the exponential change just below the fundamental absorption edge depends on the mole fraction of the microcrystaline phases.
\end{abstract}

\section{INTRODUCTION}

Recently, a number of publications have appeared that are concerned with the optical properties of small metallic and nonmetallic microcrystals. Specific attention has been paid to silicate glasses in which $\mathrm{CdS}_{\times} \mathrm{Se}_{1-x}$ microcrystalline phases are thermaliy developed. These glasses are the basis for a commercially available set of yellow-to-red sharp cut-off filters. Although several investigations have been carried out on the optical absorption, photoluminescence, and nonlinear properties in small microcrystals $[1-5]$, there are few investigations using photothermal measurements. We present here the experimental results of direct detection of the temperature changes in those glasses by using a simple photothermal spectroscopy apparatus (PTS) [6]. An externally excited solid can relax to thermal equilibriumby emission of either photons (radiative processes) or phonons (nonradiative processes). Highly sophisticated spectroscopic techniques to detect and analyze emitted photons are well established. Recently, heat production by nonradiative processes has been detected by several methods. It is worthwhile to investigate the direct detection of temperature changes resulting from nonradiative processes following light energy absorption.

(1) Present address: Daiei Denshi Co. Ltd., Saitama 344, Japan 


\section{EXPERIMENTAL}

The cell for PTS measurements is described elsewhere[6-9]. We employed a thermistor as a sensor for temperature measurements (i.e.resistance changes). PTS involves placing a thermistor in close contact with the sample and measuring temperature changes during sample irradiation with monochromatic light. In order to eliminate the effect of temperature changes of surrounding air, a differential thermistor arrangement was used to compensate for changes in ambient temperature. The thermistor has a nominal resistance of $12 \mathrm{k} \Omega$ and a sensitivity of $480 \Omega / \mathrm{K}$ at $20{ }^{\circ} \mathrm{C}$. 0ne thermistor (the working thermistor) was attached to the front of the sample. The other one (the reference thermistor) was held in place in the same manner near the working thermistor. but was not in contact with the sample. The signals were measured as the difference of the resistance between working and reference thermistors, since temperature changes in the sample resulted in an unbalance of a Wheatstone bridge which was powered by a dc source of $1.0 \mathrm{~V}$. The $1 \mathrm{ight}$ source was a 500 W short arc xenon lamp. The light beam was focused on the sample through a monochromator with light impinging on an area of $0.16 \mathrm{~cm}^{2}$. Neither thermistor was irradiated directly by the exciting beam during the experiment. PTS measurements were carried out at room temperature over the wavelength range from $400 \mathrm{~nm}$ to $900 \mathrm{~nm}$. The PTS signal intensity was always divided by the light intensity measured by a Si photodiode for normalization. The optical absorption and reflection were measured by conventional transmission and reflectance methods. A series of commercial sharp cut-off filters with a thickness of $2 \mathrm{~mm}$ were used as specimens. Electron probe microanalysis (EPMA) showed that the sulfur mole fractions $x$ in $\mathrm{CdS}_{\times} \mathrm{Se}_{1-x}$ were $1.0,0.91,0.82,0.78$ and 0.67 , respectively.

\section{RESULTS AND DISCUSSION}

Fig. 1 shows the normalized PTS signal intensities of $\mathrm{CdS}_{\times} \mathrm{Se}_{1-x}$ doped glasses as functions of photon energy in the form of semilog plots. Fig. 2 shows the total rates of optical energy absorption, $1-T-R$ ( $T$ and $R$ are transmittance and reflectance, respectively), as functions of photon energy in the form of semilog plots. Fundamental absorption edges derived from PTS agree with those derived from 1-T-R. They show blue shifts for both cases in comparison with the bulk materials. The plots of the logarithms of the normalized PTS and 1-T-R versus photon energy approach :traight 1 ines below the fundamental absorption edges. Therefore, an emirical relation for the dependence of photon energy of the PTS and $1-T-$ asignals below the fundamental absorption edges are expressed by exp (h $\left.\nu / E_{1}\right)$ where $E_{1}$ is the inverse logarithmic slope. $E_{1}$ is the parameter which shows the width of exponential change. In order to study increases 


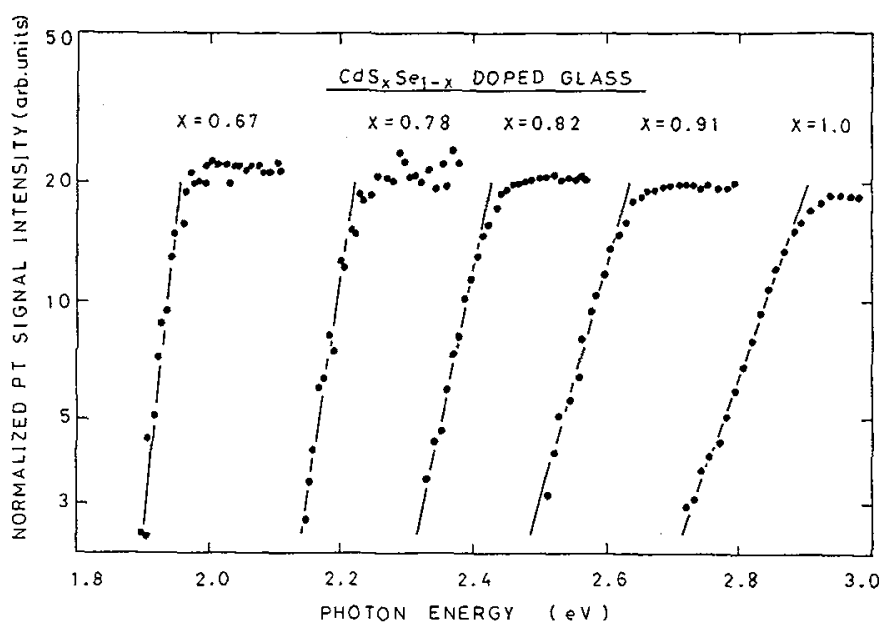

Fig. 1. Photon energy dependence of the normalized photothermal signal (PTS) for CdS $S_{1} e_{1}$ doped glasses.

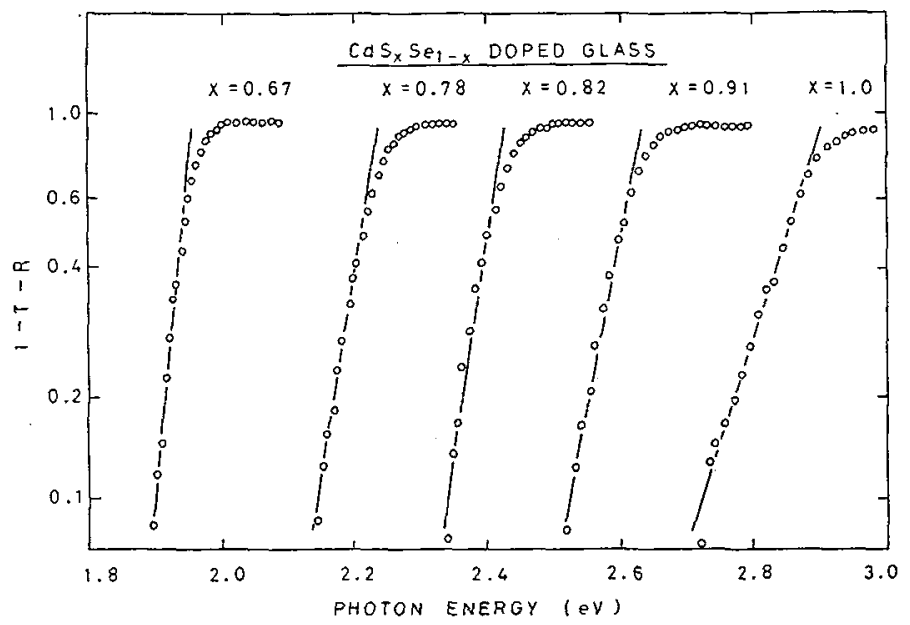

Fig. 2. Photon energy dependence of the total rate of optical energy absorption $(1-T-R)$ for $\mathrm{CdS}_{\times} \mathrm{Se}_{1-x}$ doped glasses.

and changes of both the normalized PTS and 1-T-R signals near and at the fundamental absorption edges, the parameter $E_{1}$ is derived for both cases. Fig. 3 shows the mole fraction dependence of $E_{1}$ for PTS $(O)$ and 1-T-R (O). Error bars show the probable errors. The width of the exponential change both for PTS and 1-T-R depends on the mole fraction.Fig. 3 indicates that the $E_{1}$ values from PTS measurements are larger than those for $1-T-R$ measurements, suggesting that the width of exponential changes of the former are larger than those of the latter. This fact shows a difference between the PTS and optical energy absorption characteristics. At present, the experimental results cannot be adequately explained and clari- 


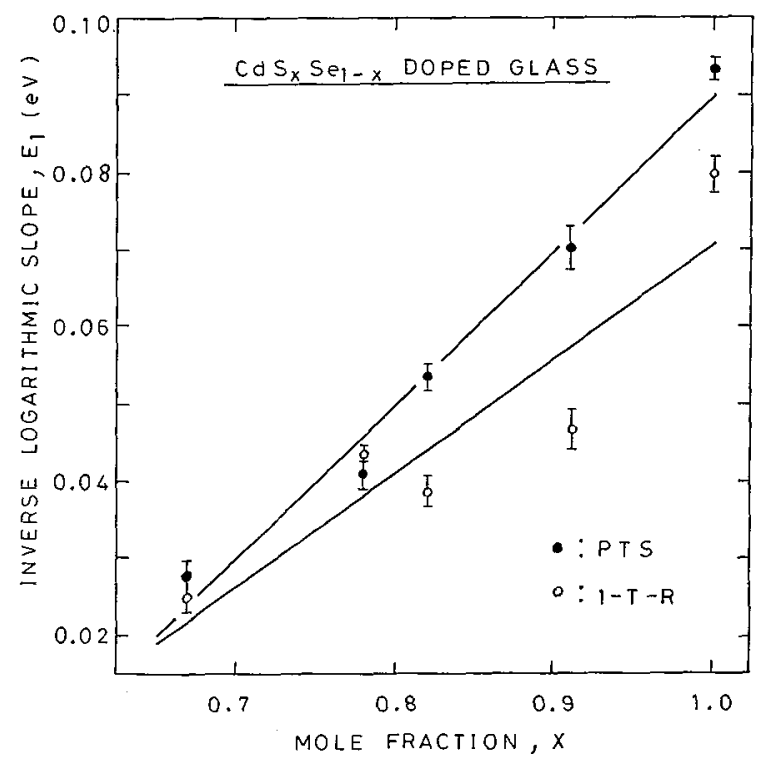

Fig. 3. Inverse logarithmic slope, E1, of the photothermal (PTS) and total rate of optical energy absorption (1-T-R) spectra for $C d S_{\times} S_{1-x}$ doped glasses.

fication of the nature of the photothermal effect in semiconductor doped glasses is left to future experimental and theoretical investigations. In the future, a study of relationships between microcluster size and photothermal (PTS, PAS etc.), photoluminescence, and excitation spectra are needed to clarify the nature of nonradiative and radiative processes in semiconductor doped glasses

\section{REFERENCES}

[1] Jain R.K. and Lind R.C., J.0pt.Soc.Am.73(1983)647-652.

[2]Brus L.E., J.Chem.Phys.80(1984)4403-4409.

[3]01bright G.R. and Peyghambarian N. . Appl.Phys. Lett.48(1986)1184-1186.

[4]Mitsunaga M, Shinokima H. and Kubodera K., J.0pt.Soc.Am.B 5(1988) 1448-1452.

[5] Tomita M., J.0pt.Soc.Am.B 6(1989)165-170.

[6]Brilmyer G.H.,Fujishima A.Santhanam K.S.V.and Bard A.J., Anal.Chem. 49 (1977)2057-2062.

[7]Fujishima A, Masuda H. and Honda K., Anal. Chem.52(1980)682-685.

[8] Brilmyer G.H. and Bard A. J., Anal, Chem. 52(1980)685-691.

[9] Fujishima A., Maeda Y. and Honda K., Bul1. Chem.Soc.Jpn.53(1980) $2735-2741$. 